\title{
Camel health management and pastoralists' knowledge and information on zoonoses and food safety risks in Isiolo County, Kenya
}

\author{
Peter Obimbo Lamuka ${ }^{1 *}$, Francis M. Njeruh², George C. Gitao ${ }^{3}$ and Khalif A. Abey ${ }^{4}$
}

\begin{abstract}
Camel health management has implications for public health and camel product trade. After liberalization of the veterinary service, current camel health management in the arid and semi-arid lands (ASALS) of Kenya and its implications for public health is not known. This study investigated camel health management and its implications on zoonoses and food safety in Isiolo County, Kenya. Semi-structured questionnaires were administered to 150 households, 15 agro-veterinary shops, 15 community-based animal health workers (CBAHWs) and 10 veterinary officers to collect information on camel health management. The main occupation and source of household income for the pastoral communities is camel-keeping (45.3\%). Pastoralists self-medicate camels and other livestock (45.8\%), which can lead to between over-dosing, under-dosing or wrong drug use. The CBAHWs, traditional animal health service providers (TAHSPs), government veterinary officers and private veterinary officers play a minimum role. Private veterinary services have not taken root in the ASALs. The sources of knowledge and information on the veterinary drug to use are experience (57.4\%), non-governmental organizations (NGO) (41.1\%) or CBAHWs (32.1\%). The majority of pastoralists (72.5\%) do not keep camel or other livestock treatment records. The constraints in purchasing veterinary drugs are expensive drugs, accessibility to drugs and availability of money. Pastoralists refer to veterinary drugs by their brand names but not by active ingredients. As reported by pastoralists, focus group discussion and key informant interviews, antibiotics used were adamycine (33.3\%), ampicilline (26.7\%), penicillin (14.4\%), tetracycline (12.2\%), amoxylin (11.1\%) and penstrip (2.2\%). The common camel diseases were trypanosomiasis, brucellosis, mastitis, diarrhoea, worm infestation, camel pox and tuberculosis. The public health risk factors were the presence of veterinary drug residues in camel products and development of resistant zoonotic organisms/diseases. It was concluded that current camel health management has serious implications for public health and food safety, and hence the camel product trade.
\end{abstract}

Keywords: Pastoralist, Camel health management, Veterinary services, Zoonoses, Food safety concerns

\section{Introduction}

The Kenyan livestock sector contributes about $10 \%$ of the gross domestic product (GDP), with the cattle dairy sub-sector contributing $3.8 \%$ of total GDP. However, the contribution of the camel dairy sub-sector is not quantified (GOK 2010).

\footnotetext{
* Correspondence: peterlamuka@gmai.com15

1 Department of Food Science, Nutrition and Technology, University of

Nairobi, P.O.Box 29053-00625, Nairobi, Nairobi, Kenya

Full list of author information is available at the end of the article
}

In Kenya, the one-humped camel (Camelus dromedarius) population is estimated to be over three million heads (KNBS 2010; FAOSTAT 2015), the third largest population in Africa after Somalia and Sudan. The camels are mainly kept as mobile grazing herds under pastoral production systems in the arid and semi-arid lands (ASALs) counties of Kenya. The ASALs are characterized by high levels of poverty, poor infrastructure, extreme weather and a fragile environment. Camels require low production inputs as they have unique adaptability to these harsh environmental conditions. Camels produce more 
milk and for a longer period than other livestock under these harsh ASAL conditions (Farah and Fisher 2004). However, this comparative advantage of camels as a milk producer over other livestock has not been adequately exploited in the improvement of the ASAL community livelihoods.

One of the major constraints is poor camel health management, which does not give consumers assurance on absence or presence of zoonotic organisms/diseases and other food safety issues. Good camel health management practices are an important factor for increased milk productivity and in promoting domestic and export milk trade (Kuria et al. 2002).

However, the privatization of veterinary services in Kenya in the 1990s (Umali et al. 1992) resulted in inadequate professional veterinary service delivery in the ASALs, as most private veterinary service providers found it not economically viable to operate in these vast areas with poor infrastructure. This had a negative impact on camel/livestock health and productivity as it hampered the provision of veterinary services and dissemination of knowledge and information on good camel health management practices to pastoralists. The result effect was mushrooming of unskilled veterinary service providers (community-based animal health workers (CBAHWs)) and self-medication of livestock, including camels. The absence of professional veterinary services results in uncontrolled and unauthorized sale of veterinary drugs by agro-veterinary shops, selfmedication, use of wrong veterinary drugs, injection needles and route, and overdosing of chemotherapeutic veterinary drugs (Kuria et al. 2002) leading to food safety concerns like drug residues and development of drug resistance among zoonotic organisms/diseases in milk and meat. Therefore, the liberalization of veterinary services in the camel sub-sector resulted in development of diseases that lowered productivity. The urban and export markets also developed negative attitudes towards camel milk and meat due to the likely presence of zoonotic organisms/diseases and food safety concerns, hence limiting the markets for camel products only to traditional consumers.

The frequent contact between livestock (camels) and humans and communal watering of livestock also facilitates spread of zoonotic organisms/diseases with a potentially high risk to public health among livestock and humans (Younan and Abdurahman 2004; Oliver et al. 2009; Kazoora et al. 2014).

Despite growing importance of the camel dairy subsector in Kenya, the effects of the post-privatization of veterinary services, current pastoralists' knowledge and information on camel health management is still limited. Most of the research conducted has documented camel husbandry practices like feeding, breeding and watering, with very little attention given to camel health management and the implication on presence or absence of zoonotic organisms/diseases and milk safety (Wanjohi et al. 2012; Wanjohi et al. 2013; Gitao et al 2013).

The present study was carried out to assess current camel health management and the impact of pastoralists' knowledge/information on zoonoses and food safety risks along the camel value chain in Isiolo County, Kenya, which is a major camel milk producing and marketing area in Kenya.

\section{Study area}

The study was carried out along the Mlango-NgarendareBurat, Kambi Garba-Ngaremara-Chumvi-Gambela and Boji-Kulamawe-Baranbate camel milk clusters in Isiolo County (Figure 1).

Isiolo County is a typical ASAL area located in the northern eastern region of Kenya and covers approximately $25,000 \mathrm{~km}^{2}$. The County has a population of approximately 43,300 camels, kept under peri-urban and pastoral camel production systems. Isiolo County has a thriving camel milk production and marketing business. It supplies $90 \%$ of camel milk to the Nairobi terminal camel milk market.

The rainfall pattern is bimodal (350 and $600 \mathrm{~mm}$ per year), unpredictable and erratic in distribution. Long rains occur in late March to May while short rains occur in November to December. The County experiences recurring droughts with devastating losses of livestock. The mean annual temperature is between 24 and $30{ }^{\circ} \mathrm{C}$ (Herlocker et al. 1993).

\section{Methods}

\section{Study design and data collection}

A cross-sectional survey was conducted among 150 camel-keeping households, 15 agro-veterinary outlets/ shops, 15 community-based animal health workers and 10 veterinary officers were conveniently selected along the Mlango-Ngarendare-Burat, Kambi Garba-NgaremaraChumvi-Gambela and Boji-Kulamawe-Baranbate camel milk clusters in Isiolo County. The households were conveniently selected from each of the above clusters based on the Kenya population census clustering system (KNBS 2010), accessibility and the willingness of pastoralists to take part in the study.

One set of semi-structured questionnaires were administered to 150 camel-keeping households to obtain information on camel health management practices and knowledge/information of pastoralists on the right veterinary practices in camel health management, zoonotic organisms/diseases and food safety risks. The practices determined were who treats camel/livestock, sources of veterinary drugs for treating the camel/ livestock, source of knowledge and information on veterinary drug use, type of records kept when treating 


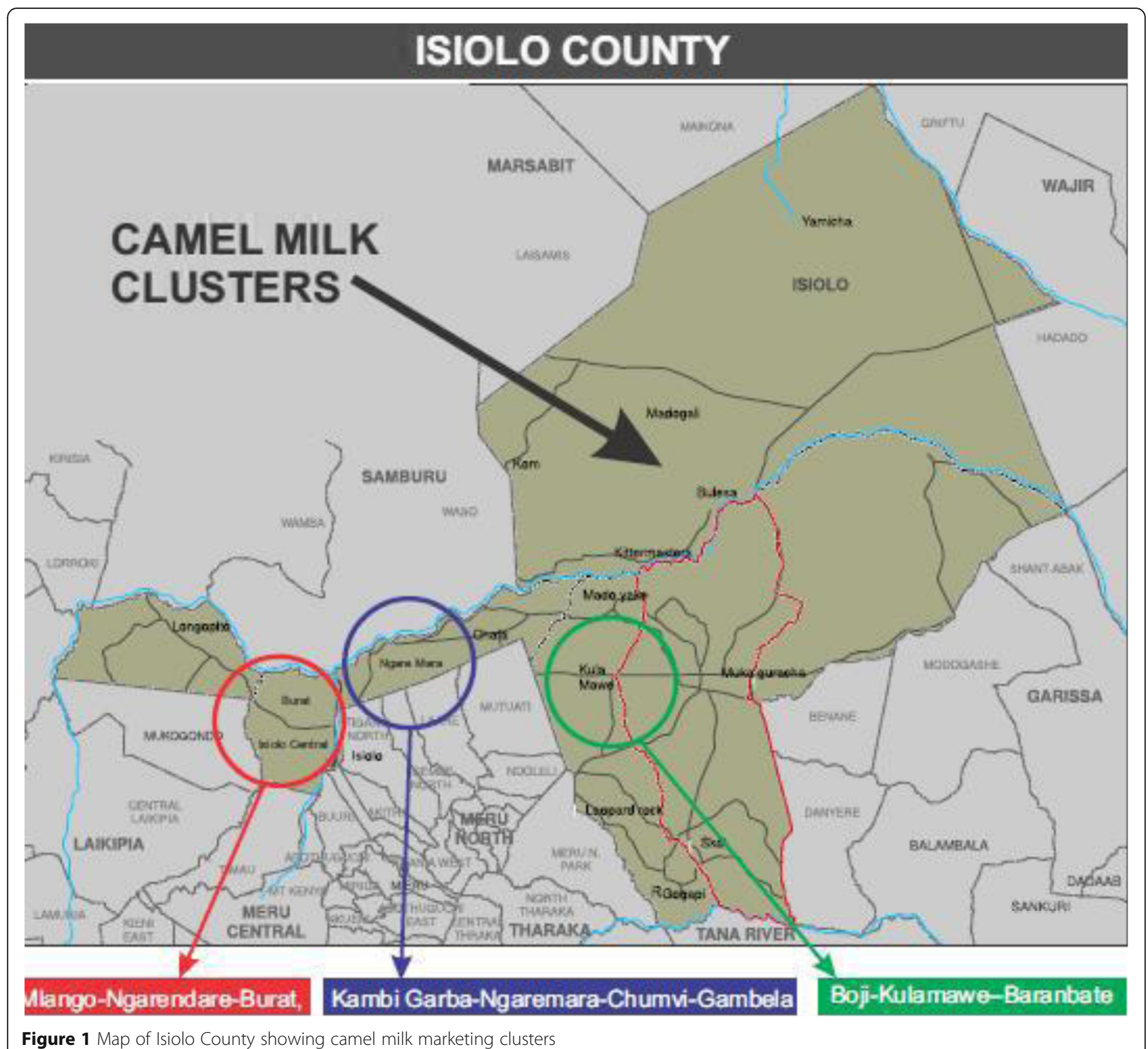

camel/livestock and constraints in purchasing of veterinary drugs as dependent variables. These practices if not professionally done will result in drug residues in camel milk and meat and development of drug resistant zoonotic organisms with serious implications for food safety.

Knowledge and information of pastoralists on camel husbandry practices associated with spread of zoonotic organisms/diseases was determined. Also, knowledge of pastoralists on potential food safety risk along the camel milk value chain, milk withdrawal period after treatment of camels, presence of drug residues and drug resistance was determined.

Another set of different semi-structured questionnaires were administered specifically to 15 agro- veterinary outlets/shops, 15 community-based animal health workers and 10 veterinary officers to elicit their knowledge/information on provision of veterinary services, types of diseases commonly affecting camels, types of veterinary drugs commonly used, dosage used in treatment of camels and practices that predispose camel and pastoralists to zoonotic diseases, as dependent variables.

Focus group discussions (FGDs) and key informant interviews (KIIs) were conducted to complement the information gathered through the semi-structured questionnaires. The FGDs and KIIs comments were also used to clarify and give more insights on aspects of camel health management practices, zoonoses and food safety risk factors. 


\section{Statistical analysis}

The frequencies of respondents' responses were determined and corresponding proportions (percentage) of responses calculated for individual variables and histograms drawn using Excel software. The dependent variables were: who treats camel/livestock, sources of veterinary drugs for treating the camel/livestock, source of knowledge and information on veterinary drug use, type of records kept when treating camel/livestock and constraints in purchasing of veterinary drugs. The independent variables were age, gender and level of education. Correlations and Pearson's correlation coefficient were calculated to measure the strength and direction of the relationship between dependent and independent variables.

\section{Results}

\section{Demographic and socio-economic characteristics}

Table 1 shows the gender, ethnic group, education and socio-economic characteristics ofthe surveyed pastoralists. The respondents consisted of $52 \%$ male and $48 \%$ female. The majority of respondents were of Somali (70\%), Garri, a sub-tribe of Somali descent (16\%) and Boran (10\%)

Table 1 Demographic and socio-economic characteristics of respondents

\begin{tabular}{|c|c|c|c|}
\hline Characteristics & & Frequency & Percent \\
\hline \multirow[t]{2}{*}{ Gender $(n=150)$} & Male & 78 & 52.0 \\
\hline & Female & 72 & 48.0 \\
\hline \multirow[t]{2}{*}{ Household heads $(n=150)$} & Yes & 98 & 65.3 \\
\hline & No & 52 & 34.7 \\
\hline \multirow{3}{*}{$\begin{array}{l}\text { Relationship to household } \\
\text { head }(n=52)\end{array}$} & Spouse & 43 & 82.7 \\
\hline & Son & 6 & 11.5 \\
\hline & Others & 3 & 5.8 \\
\hline \multirow[t]{4}{*}{ Ethnic origin } & Somali & 105 & 70.0 \\
\hline & Garri & 24 & 16.0 \\
\hline & Boran & 15 & 10.0 \\
\hline & Sakuye & 6 & 4.0 \\
\hline \multirow[t]{4}{*}{ Education } & No formal education & 99 & 66.0 \\
\hline & Pre-primary & 24 & 16.0 \\
\hline & Primary & 15 & 10.0 \\
\hline & Secondary level & 12 & 8.0 \\
\hline \multirow[t]{4}{*}{ Occupation ( $n=150$ ) } & Livestock keeping & 100 & 66.7 \\
\hline & Self-employment & 24 & 16.0 \\
\hline & Salaried-employment & 20 & 13.3 \\
\hline & Others & 6 & 4.0 \\
\hline \multirow[t]{5}{*}{ Sources of income } & Livestock & 67 & 44.7 \\
\hline & Income from business & 50 & 33.3 \\
\hline & Food aid & 14 & 9.4 \\
\hline & Salary & 10 & 6.6 \\
\hline & Crops & 9 & 6.0 \\
\hline
\end{tabular}

ethnic groups. A high percentage of respondents (66\%) had no formal education. The main occupation of the household heads was livestock-keeping (70\%), with selfemployment (16\%) and salaried-employment (12.7\%) as other occupations. Livestock-keeping contributes about $44.7 \%$ towards households' income on average, of which camels contributed $45.3 \%$, goats and sheep contributed $32.7 \%$ and income from business contributing 33.3\% towards households' income. Drought (34.6\%), livestock diseases (33.4\%) and insecurity (32\%) have nearly equal implications for household income generation, due to either death of livestock or loss of livestock due to livestock theft.

\section{Treatment of camels and other livestock}

The treatment of camels and other livestock is mostly done by pastoralists themselves, (45.8\%) (self-medication), and also by CBAHWs (16.7\%) or traditional animal health service providers (TAHSP) (15.3\%) but very few remaining government veterinary officers (12.5\%) (Figure 2). Provision of veterinary clinical services from private professional veterinary officers is minimal (9.7\%), indicating that private veterinary practice has not taken root in the ASALs.

\section{Knowledge and information on the right veterinary drugs to use}

Most of the pastoralists (57.4\%) acquired knowledge/information on veterinary drug use through experience and previous conduct with past professional government veterinary officers (Figure 3 ). There was highly significant $(p<0.001)$ difference and negative correlation $(r=-0.309)$ between age and sources of knowledge and information on treating camels. Only $18.5 \%$ of pastoralists had some knowledge/information on the right veterinary drug to use, which they acquired through informal training

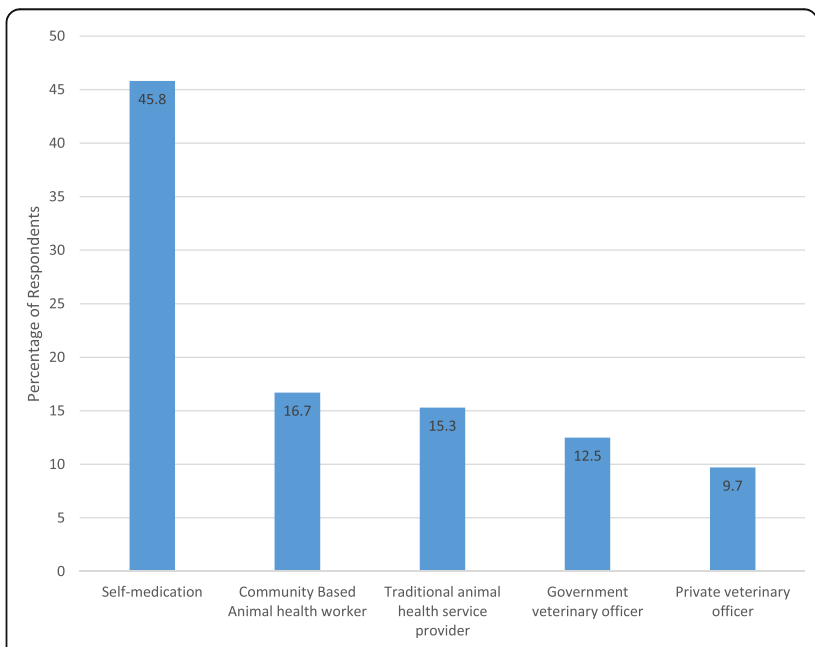

Figure 2 Percentage of contribution of Veterinary Service Providers in camel/livestock treatment 


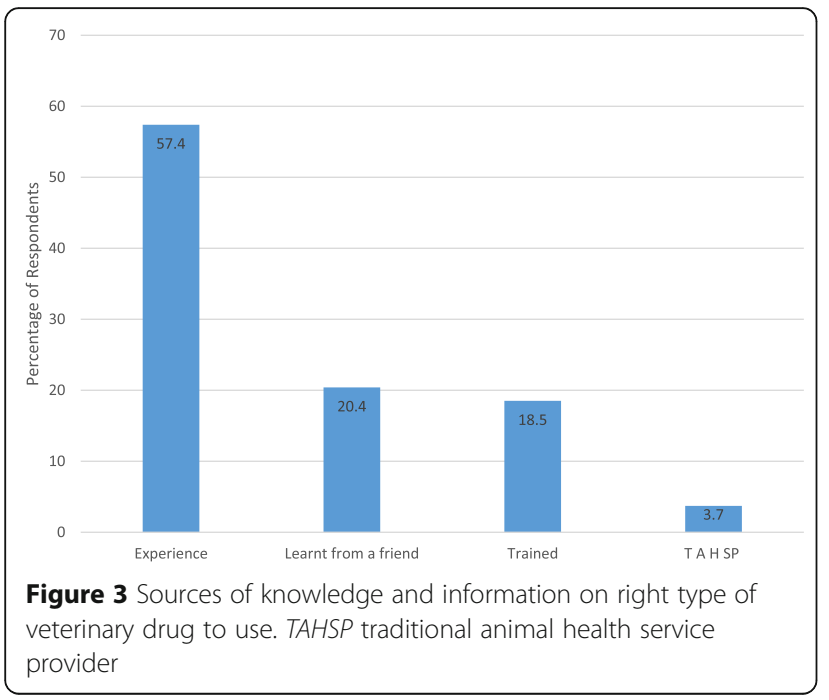

(Figure 3) provided by either non-governmental organization (NGO) $(41.1 \%)$ or CBAHWs (32.1\%) (Figure 4). There was significant $(p=<0.05)$ difference and negative correlation $(r=-0.387)$ between level of education and knowledge and information on the right veterinary drug to use.

There was very little involvement of either the national or the County government in provision of information on the right veterinary drug to use $(7.1 \%)$ to pastoralists (Figure 4). The veterinary drug stores/agro-veterinary shops are mostly staffed by personnel with nil or minimum knowledge on clinical veterinary services.

\section{Sources of drugs for treating camels and other livestock}

Eighty percent $(80 \%)$ of pastoralists reported that they purchase veterinary drugs from agro-veterinary shops, while else received from $\mathrm{NGO/donor} \mathrm{projects} \mathrm{(11.4 \% )} \mathrm{or}$

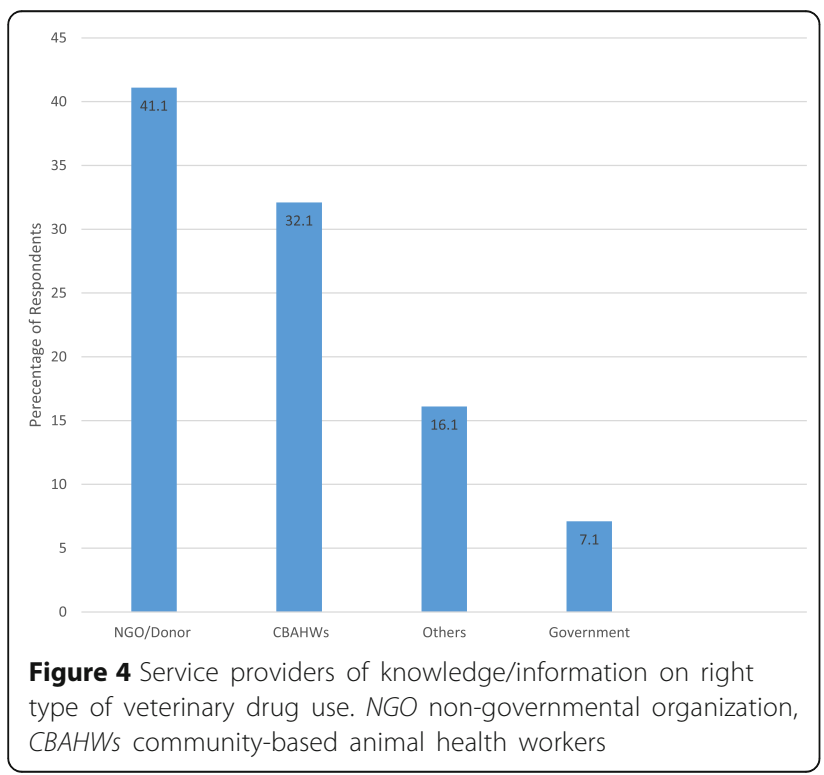

other sources (8.6\%) such as friends/neighbours with previous leftover stock. There was significant $(p=<0.05)$ difference and negative correlation $(r=-0.300)$ between age and sources of veterinary drugs for treating camels, indicating that youth and elderly herders get veterinary drugs from several sources.

\section{Constraints in purchasing veterinary drugs}

The distance on average to the nearest veterinary drug stores was more than $20 \mathrm{~km}(43.2 \%)$, with $20.3 \%$ and $21.6 \%$ of respondents being 1 to $5 \mathrm{~km}$ and 11 to $20 \mathrm{~km}$ away from veterinary drug stores, respectively. There was no significant $(p>0.05)$ difference and negative correlation between level of education and accessibility to veterinary drug store $(r=-0.263)$ or in constraints of getting veterinary drugs $(r=-0.347)$. Despite the long distances to the nearest drug store, the high cost of veterinary drugs $(49 \%)$ was the main constraint faced by pastoralists when purchasing veterinary drugs, compared to accessibility to veterinary drugs $(32.4 \%)$ or availability of money to purchase the veterinary drugs (18\%) (Figure 5).

\section{Type of records kept when treating camels and other livestock}

Most of the pastoralists (72.5\%) do not keep records on treatment of camels and other livestock. There was no significant $(p>0.05)$ difference and negative correlation $(r=-1.000)$ between level of education and types of record kept when treating camel. Of the $25.5 \%$ who kept records, 17.4, 47.8 and 25\% kept records on type of diseases, type of veterinary drugs used and when the camel got sick, respectively (Figure 6).

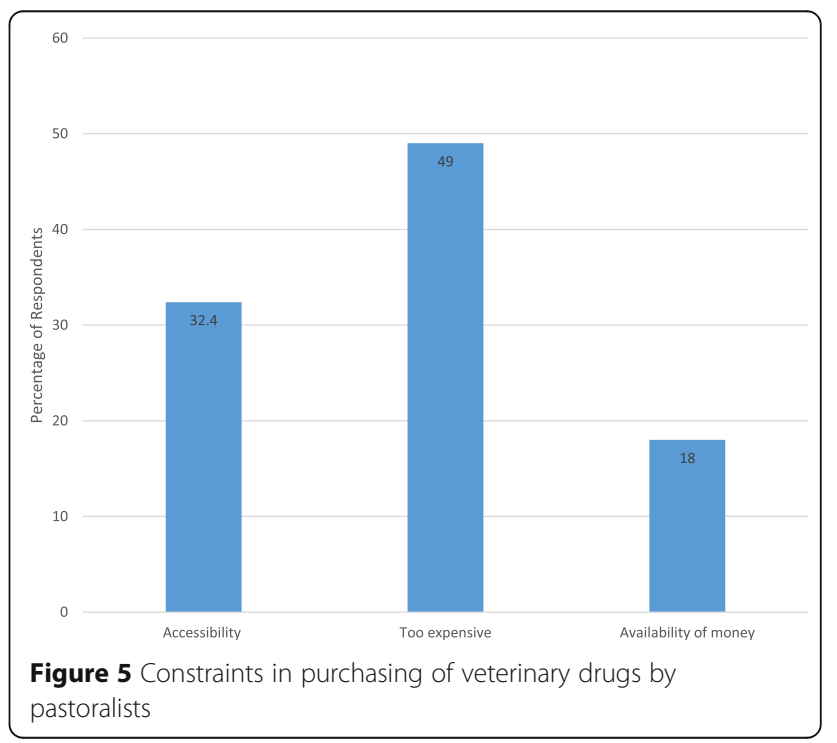




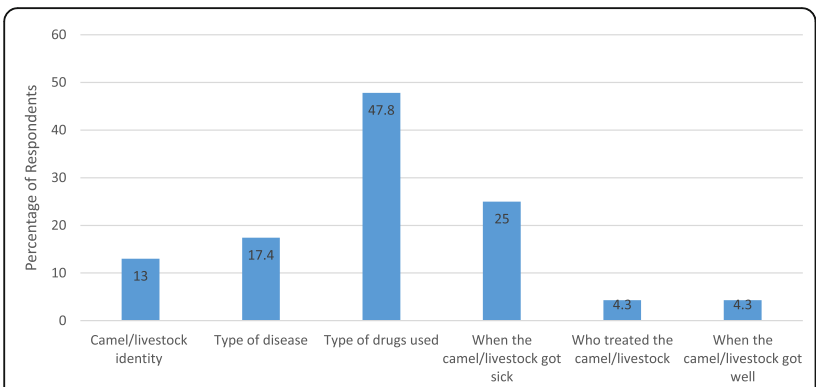

Figure $\mathbf{6}$ Type of records kept by pastoralists when treating livestock/camel

\section{Diseases commonly affecting camels in the study area}

The common diseases that infect camels in the study area were listed by pastoralists as trypanosomiasis (39\%), brucellosis (14\%), mastitis (10\%), diarrhoea (10\%), worm infestation (9\%), camel pox (4\%) and tuberculosis (3\%). Most of the respondents were not aware of incidences of bovine tuberculosis in camels. There was no significant $(p>0.05)$ difference and negative correlation between level of education and pastoralists knowing diseases that affect camels in the study area $(r=-0.312)$ or knowing whether brucella, tuberculosis (TB) and mastitis affect camels in the study area $(r=-0.352)$.

\section{Types of drug used}

There was no significant $(p>0.05)$ difference and negative correlation between level of education and the pastoralists knowing types of drugs used to treat camels $(r=-0.447)$ and whether antibiotics $(r=-0.254)$ are used to treat camels. Ninety percent (90\%) of pastoralists reported to have used veterinary drugs during treatment of their camels or other livestock. However, the respondents could only refer to the veterinary drugs by their brand names. The active ingredients on the brand were determined by cross-checking on packages at agrovet shops and consultation with veterinary professionals at the Department of Clinical Studies, University of Nairobi. Apart from triquin (11.9\%), which is used in treatment of trypanosomiasis, the penstrip (2.2\%), tetracycline (12.2\%), ampicilline (26.7\%), adamycine (33.3\%), penicillin (14.4\%) and amoxylin (11.1\%) were common antibiotics used in treatment of camels or other livestock (Figure 7). This information was complemented by agro-veterinary shop attendants who also reported selling the same veterinary drugs in nearly the same proportion (Figure 8).

Risk factors associated with residual veterinary drugs and spread of zoonotic organisms/diseases

Thirty-six percent $(36.2 \%)$ of respondents reported that presence of veterinary drug residues in camel milk and meat was a health risk to human and camels (Figure 9).

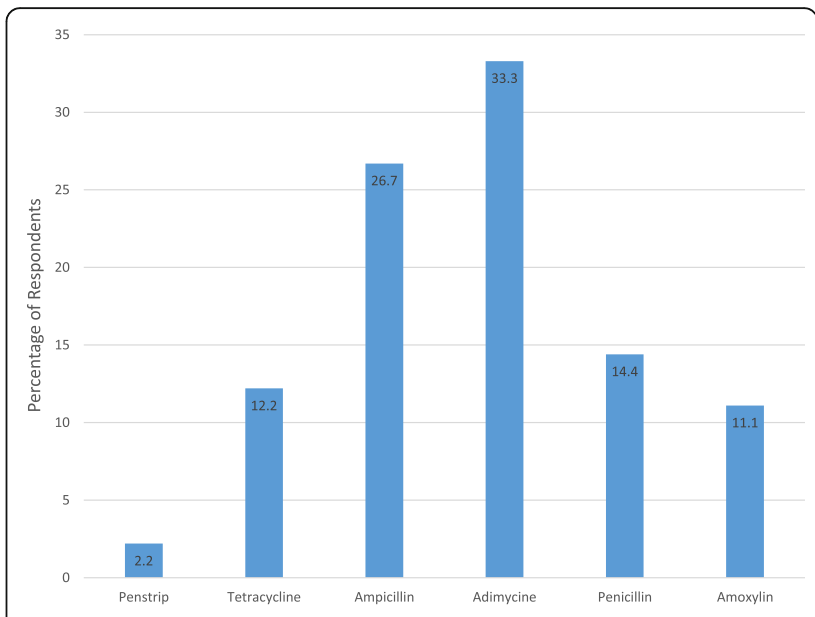

Figure 7 Types of drugs commonly used by pastoralists in treating camel/livestock

About $34.5 \%$ were not sure of the impact of veterinary drug residues on human and camel health. There was no significant $(p>0.05)$ difference but there was negative correlation $(r=-0.312)$ between level of education and likely presence of residual veterinary drugs in camel milk $(r=-0.447)$ knowing that presence of residual veterinary drugs in camel milk is a risk $(r=-0.339)$. The health risks cited were diarrhoea/vomiting (44.7\%), allergic reaction $(31.6 \%)$ resistance to human and veterinary drugs $(15.8 \%)$ and cancer $(7.9 \%)$.

\section{Health risk to human and camels}

Forty-eight percent (48\%) of pastoralists reported having received advice from veterinary service providers on milk withdrawal period after treatment of camels or other livestock. Of the $48 \%$ who had received this advice, about $53 \%$ of pastoralists reported to have been advised not to consume or sell camel milk one day

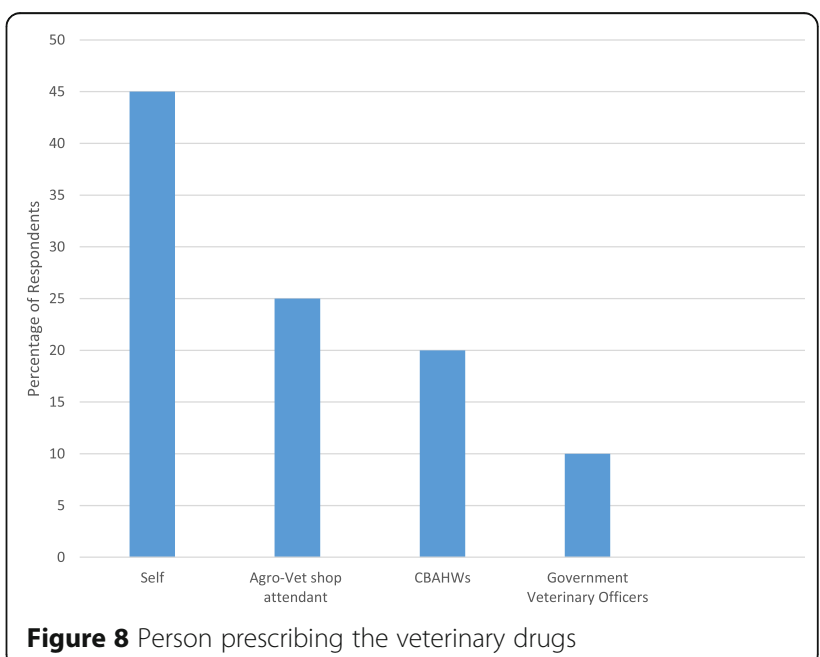




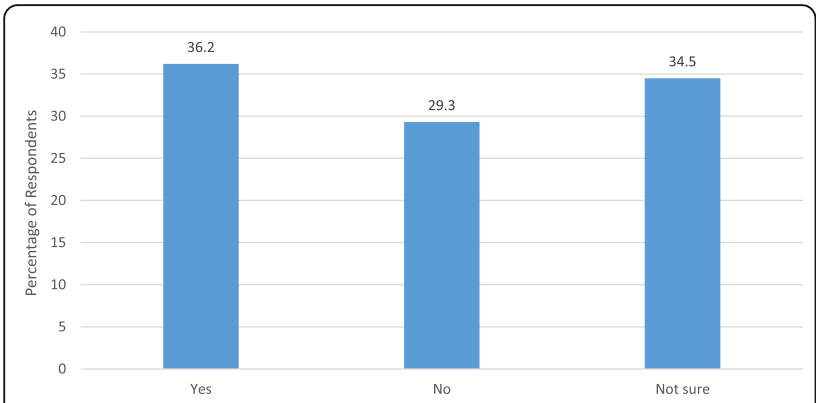

Figure 9 Percentage of respondents citing that presence of veterinary drug residues was health risk to human and camels

(15.2\%), three days (51.5\%) and five days (30.3\%) after treatment of camels with antibiotics.

Common foodborne diseases encountered in the study area Twenty-three percent of pastoralists reported that one of their family members or person from the study area had a health problem associated with camels. (Figure 9). Out of these $23 \%$ of pastoralists, $72.7,81.8,26.4,45.4$ and $27.3 \%$ of respondents reported incidences of bloody diarrhoea, brucellosis, tuberculosis, septic sore throat and kidney failure, respectively, among either family members or any other persons in the study area. There was no significant $(p>0.05)$ difference and negative correlation $(r=-0.312)$ between level of education knowing whether brucellosis, TB and kidney failure affect humans. According to key informants at the county health office, there are high incidences of brucellosis and tuberculosis in the County (read Kenya as, most Kenyans commonly referred to brucellosis as "milk disease").

\section{Focus group discussion and key informant interview}

During focus group discussions (FGD) and key informant interviews (KIIs), gross misuse and abuse of veterinary drugs by pastoralists was reported. The noted cases were administering veterinary drugs through a wrong route and using a wrong injection needle size. The pastoralists, CBAHWs and veterinary officers complained that most of the veterinary drug packages in agro-veterinary shops did not have instructions on dosage for camels, and they extrapolate the camel dosage based on cattle or horse dosage on the package, which can lead to over-dosing or under-dosing of camels.

During FGD and KIIs, the respondents cited several barriers to availability and appropriate prescription of veterinary drugs by agro-veterinary outlets. These include unavailability of veterinary drugs, price competition among agro-veterinary outlets, economic constraints and limited pastoralists' knowledge on drug use and camel diseases. The veterinary officers expressed mistrust towards competency of non-professional practitioners. The agro-veterinary drug outlets reported that professional veterinarians and para-veterinarians were important players in promoting the pastoralists' management of camel and other livestock health.

The risk factors associated with spread of zoonotic organisms/diseases between human and camel/livestock were identified by veterinary service providers and KIIs as: livestock and wildlife common grazing and watering points, mixing of infected and healthy camels and other livestock herds at grazing and watering points, humans sharing water sources for personal hygiene and domestic use with camels and other livestock, aerogenic transmission due to close contact of camels and herders in the night housing "boma", herders assisting camels during delivery and training young camels how to take water and suckle the mother.

\section{Discussion}

\section{Demographic and socio-economic characteristics}

There is equal and highly significant $(p=<0.001, p=$ -0.359) participation of male, women and youth in camelkeeping activities. However, according to traditions of Somali and Boran pastoral communities, daughters should play limited roles in camel and other livestock management. Therefore, for development of commercially viable camel product system, women should be considered seriously in the transformation of the camel value chain. The predominant camel keepers are the Somali ethnic group, but due to recurrent drought and adaptability of camels to the ASAL conditions, the Boran ethnic group, although traditionally cattle-keepers, are slowly adapting to camel keeping (Noor et al. 2013).

There was highly significant $(p<0.001, r=-0.309)$ correlation between age and pastoralists knowledge and information on treating camels. Lack of formal education or low level of education among pastoralists affects their ability to acquire, comprehend and disseminate knowledge and information on camel health management and food safety awareness. It also hampers their ability to interact with professional veterinary staff.

The results of this study are in agreement with studies by Kaufmann (1998), Musinga et al. (2008), Wayua et al. (2012) and Watete et al. (2016), who reported that livestock-keeping, especially camel-keeping, is the main occupation and source of household income for the pastoral communities. Camels are adapted to harsh ASAL conditions; therefore, interventions aimed at improving the camel value chain need to consider the promotion of camel health management as an option for building pastoralists' resilience against climate change.

\section{Treatment of camels and other livestock}

The results are in agreement with the findings of Onono et al. (2015) who reported that treatment of cattle in 
Narok County was done by male pastoralists. The pastoralists' self-medication of their camel and other livestock poses serious public health risks due to use of the wrong veterinary drugs, over-dosing and under-dosing. The over- or under-dosing of camels is complicated by lack of camel dosage information on most drug packages, hence extrapolation of camel dosages based on cattle or horse dosage, which can lead to over-dosing and under-dosing. The presence of veterinary drug residues in camels and camel milk and meat can lead to development of drug resistant organisms in both the camels and the humans consuming camel products. This can result in development of drug- resistant zoonotic organisms in the camel. When camel products are consumed, the drug- resistant foodborne organisms are then transmitted to human consumers, thus posing a food safety and public health issue. Inappropriate and inefficient use of veterinary drugs has been reported to have devastating effects on animal disease management (Redding et al. 2013).

This study shows that CBAHWs are the main providers of animal health services, apart from the pastoralists themselves. The private clinical veterinary practices are unsustainable in the ASALs. This is due to the nomadic nature of the pastoral systems and disproportionately high expenses involved in transport and time involved in tracing the camels and other livesock animal (FAO 2001; Chema and Gathuma 2004; Woodford 2004; Onono et al. 2015). CBAHWs have been reported as an alternative animal health service providers in smallholder farming sectors in Zimbabwe (Matambara et al. 2013) and reported to be technically competent in Mwingi County, Kenya (The IDL Group and McCorkle C 2002; Rubyogo et al. 2005).

Recognition of CBAHWs as Para-Veterinary Professionals is not defined in the Veterinary Surgeons and Veterinary Para-Professionals Regulations, Legal Notice no. 48 (GOK 2013), making their services illegal. The statutory bodies like the Kenya Veterinary Board (KVB) and Kenya Veterinary Association (KVA) also state that the CBAHW approach does not fit within the existing technical, legal and policy framework of animal health delivery (Mugunieri et al. 2004a). Therefore, there is a need for policy change to integrate CBAHWs in the existing formal animal health service delivery in pastoral areas of Kenya (Mugunieri et al. 2004b; Ahuja 2004).

\section{Knowledge and information on the right veterinary drug to use}

In the ASALs, there is limited dissemination of knowledge and information on camel health management. Pastoralists obtain knowledge and information on veterinary drug use through experience (the elders have more information on veterinary drugs than the youth).
Pastoralists also get knowledge/information on veterinary drug use through informal training conducted by either NGOs or CBAHWs recruited as facilitators by NGOs. This demonstrates the significant role played by the CBAHWs in animal health management in the ASALs. There is limited involvement of the government in provision of knowledge and information on the right veterinary drugs to use.

\section{Sources of veterinary drugs for treating the camel/ livestock and constraints in purchasing veterinary drugs} There was no significant differences in different ways of accessibility ( $p>0.05, r=-0.263)$ to veterinary drug stores or constraints $(p>0.05, r=-0.347)$ involved in getting veterinary drugs. The high cost of drugs is the main constraint compared to accessibility to veterinary stores. Pastoralists do not factor transport into overall costs, due to daily delivery of milk to urban centres located in the same urban and peri-urban centres where the veterinary drug stores are located. Key informant interviews revealed that camel-keepers spend more money on camel health care and watering of camel than on feeds. This corroborates the findings of Heffernan (2004) who reported that livestock owners have increased household expenditures for animal healthcare, feed and water. Heffernan and Misturelli (2000) reported that expenditure on livestock drugs was ranked fourth after food, school fees and human health in the tier of pastoralists' expenditure.

The regulations on provision and sale of livestock drugs in Kenya are very weak, allowing for unqualified persons to establish and manage outlets selling veterinary pharmaceuticals. This leads to extensive misuse and abuse of veterinary drugs due to lack of dissemination of knowledge and information to pastoralists when administering the veterinary drugs.

\section{Treatment records and diseases commonly affecting camels in the study area}

Lack of records on treatment of livestock/camels may be attributed to lack of education and low education level of pastoralist communities. The lack of records has serious implications on traceability of diseases and veterinary drug use, thus affecting international safety requirements.

The study findings indicate that the pastoralists are more familiar with the common diseases like mastitis, brucellosis and diarrhoea than with the rare diseases like bovine tuberculosis and listeriosis in animals/camels. Woldearegay et al. (2015) reported that in Ethiopia, pastoralists apply prophylactic treatments (49.4\%) and deworming (89.8\%) to control bacterial infection and parasitic diseases of camels, respectively. 


\section{Health risk factors and food safety concerns}

The health risk factors were veterinary drug residues in camel milk and meat, diarrhoea/vomiting, allergic reaction, resistance to human and veterinary drugs and cancer. The presence of these public health and food safety risk factors demonstrates the likelihood of spreading zoonotic diseases between animals and human. The presence of veterinary drug residuals may lead to development of resistance in the common diseases affecting the livestock and humans in the study area.

\section{Conclusions}

Pastoralists self-medicate camels despite having limited knowledge and information on camel health management. Pastoralists also do not receive any government or private professional veterinary services in management of camel health. These pose serious public health risk and food safety concerns in the camel value chain. Therefore, to support the development of camel value chain, effective strategies that support improved management of camel health should be promoted.

\section{Acknowledgements}

We thank AA of Kenya Camel Association for his assistance with the field logistics and data collection. We also wish to thank all enumerators, herders and pastoralists for their willingness to participate in the study.

\section{Funding}

This study was supported by the funds from National Council of Science, Technology and Innovation (NACOSTI), Kenya. The funding agency was not involved in the collection, analysis and interpretation of the data and in writing the manuscript.

\section{Authors' contributions}

All authors read and approved the final manuscript.

\section{Authors' information \\ POL (MSC Food Safety) is a Lecturer and affiliated to the Department of Food Science, Nutrition and Technology, University of Nairobi, and is undertaking his PhD studies in Veterinary Public Health. FMN (PhD) is a Professor affiliated to the Department of Public Health, Pharmacology and Toxicology, University of Nairobi. GCG (PhD) is an Associate Professor affiliated to the Department of Veterinary Pathology, Microbiology and Parasitology, University of Nairobi. KAA is a Technical Representative of Kenya Camel Association.}

\section{Competing interests}

The authors declare that they have no competing interests.

\section{Ethics approval and consent to participate}

Ethical clearance for the study was approved by the Biosafety, Animal Use and Ethics Committee of the Faculty of Veterinary Medicine, University of Nairobi, Kenya.

\section{Publisher's Note}

Springer Nature remains neutral with regard to jurisdictional claims in published maps and institutional affiliations.

\section{Author details}

'Department of Food Science, Nutrition and Technology, University of Nairobi, P.O.Box 29053-00625, Nairobi, Nairobi, Kenya. 'Department of Public Health, Pharmacology and Toxicology, University of Nairobi, P.O.Box 29053 00625, Nairobi, Nairobi, Kenya. ${ }^{3}$ Department of Veterinary Parasitology and Microbiology, University of Nairobi, P.O.Box 29053 - 00625, Nairobi, Nairobi,
Kenya. ${ }^{4}$ Kenya Camel Association, P.O. Box 6067-00100, Nairobi, Nairobi, Kenya.

Received: 5 November 2016 Accepted: 15 June 2017

Published online: 02 August 2017

\section{References}

Ahuja, V. 2004. The economic rationale of public and private sector roles in the provision of animal health services. Scientific and Technical Review of the Office International des Epizooties 23(1): 33-45.

Chema, S., and J.M. Gathuma. 2004. Kenya: The development of private services and the role of the Kenya Veterinary Association. Scientific and Technical Review of the Office International des Epizooties 23(1): 331-340.

FAO. 2001. Veterinary services. Chapter 10. In Reform and decentralization of agricultural services: A policy framework. FAO agricultural policy and economic development series No. 7. Rome: Agriculture and Economic Development Analysis Division, Food and Agriculture Organization.

FAOSTAT. 2015. Food and agriculture organization statistical database.. http://www.fastat.fao.org/. Accessed 23 Aug 2015.

Farah, Z., and A. Fisher. 2004. The camel (C. dromedarius) as a meat and milk animal. In Handbook on products and processing, ed. Z. Farah and A. Fischer, 25-28. Zurich: ETH.

Gitao, CG, LC Bebora, and G Wanjohi. 2013. Camel milk hygiene. Analysis of camel milk contamination in Garissa and Wajir Counties. Saarbrücken: LAP Lambert Academic Publishing.

GOK, 2010. Kenya National Dairy Master Plan. Volume 1: A situational analysis of the dairy subsector. Government Press, Republic of Kenya, Nairobi. Kenya.

GOK. 2013. The Veterinary Surgeons and Veterinary Para-Professionals Regulations, Legal Notice No. 48, 14th March, 2013. Nairobi: Government Press.

Herlocker, D, S Shaaban, and S Wilkes. 1993. Range management handbook of Kenya. Volume II, Isiolo District. Nairobi: Ministry of Agriculture, Livestock Development and Marketing.

Kaufmann, B. 1998. Analysis of pastoral camel husbandry in Northern Kenya. Hohenheim Tropical Agricultural Series No. 5. Weikersheim: Verlag Josef Margraf.

Heffernan, C. 2004. Livestock and the Poor: Issues in poverty-focused livestock development. Chapter 15, In: Responding to the Livestock Revolution: the role of globalisation and implications for poverty alleviation. Eds. E. Owen, T. Smith, M.A. Steele, S. Anderson, A.J. Duncan, M. Herrero, J.D. Leaver, C.K. Reynolds, J.I. Richards, J.C. Ku-Vera. British Society of Animal Science, publication 33.

Heffernan, C. and Misturelli, F., 2000. The Delivery of veterinary services to the poor: Findings from Kenya. Report for the DFID Animal Health Programme, University of Edinburgh.

Kazoora, H.B., S. Majalija, N. Kiwanuka, and J.B. Kaneene. 2014. Prevalence of Mycobacterium bovis skin positivity and associated risk factors in cattle from Western Uganda. Tropical Animal Health and Production 46(8): 1383-139.

KNBS. 2010. Kenya 2009 population and housing census. Vol II: Population and household distribution by socio-economic characteristics. Kenya National Bureau of Statistics, Government of Kenya.

Kuria, J.K.N., J.M. Nginyi, and D.K. Nganga. 2002. The role of agro-veterinary shops (dukas) in the delivery of animal health services and information. In Proceedings of Stakeholders Workshop, 22-23 May, pp77. Nakuru, Kenya.

Mugunieri, GL, P Irungu, and JM Omiti. 2004a. Performance of community-based animal health workers in the delivery of livestock health services. Tropical Animal Health and Production 36(6): 523-35.

Mugunieri, GL, J Omiti, and P Irungu. 2004b. Integrating community-based animal health workers into the formal veterinary service delivery system in Kenya. Agrekon 43(1): 89-100

Musinga M, Kimenye D and P Kivolonzi. 2008. The camel milk industry in Kenya: Results of a study commissioned by SNV to explore the potential of camel milk from Isiolo district to access sustainable formal markets. Final Report prepared by Resource Mobilisation Centre, pp15-17, Nanyuki, Kenya.

Mutambara J, I Dube, E Matangi and F Majeke. 2013. Factors influencing the demand of the service of community based animal health care in Zimbabwe. Preventive Veterinary Medicine. 11 2(3-4):174-82.

Noor, I.M., A. Guliye, M. Tariq, and B. Bebe. 2013. Assessment of camel and camel milk marketing practices in an emerging peri-urban production system in Isiolo County, Kenya. Pastoralism: Research, Policy and Practice 3: 1-8. doi:10.1186/2041-7136-3-28. 
Oliver, S.P., K.J. Boor, S.C. Murphy, and S.E. Murinda. 2009. Food safety hazards associated with consumption of raw milk. Foodborne Pathogens and Disease 6: 793-806.

Onono, J.O., J.O. Amimo, and J. Rushton. 2015. Constraints and efficiency of cattle marketing in semiarid pastoral system in Kenya. Tropical Animal Health and Production 47(4): 691-697. doi:10.1007/s11250-015-0779-6,

Redding, L.E., F.K. Barg, G. Smith, D.T. Galligan, M.Z. Levy, and S. Hennessy 2013. The role of veterinarians and feed-store vendors in the prescription and use of antibiotics on small dairy farms in rural Peru. Journal of Dairy Science 96(11): 7349-7354.

Rubyogo, J.C., P.M. Murithii, G.J. Agumbah, and G. Obhai. 2005. Assessment of the technical competence and ethical behaviour of community-based animal health workers in Mwingi District, Kenya. Tropical Animal Health and Production 37(4): 267-76.

The IDL Group, and C. McCorkle. 2002. Community-based animal healthcare, participation, and policy: Where are we now? In Community-based animal healthcare. PLA notes, No. 45. London: International Institute for Environment and Development.

Umali, D., G. Feder, and C. de Haan. 1992. The balance between public and private sector activities in the delivery of livestock services. Discussion Paper 163. Washington DC: World Bank.

Wanjohi, M., C.G. Gitao, and L. Bebora. 2012. The prevalence of Brucella spp in camel milk marketed from North Eastern Province Kenya. Research Opinion in Animal and Veterinary Science 2(7): 425-434.

Wanjohi, M., C.G. Gitao, and L.C. Bebora. 2013. Sub clinical mastitis affecting hygienic quality of marketed camel milk from North-Eastern Province, Kenya. Microbiology Research International 1(1): 6-15.

Watete, P.W., W. Kogi Makau, J.T. Njoka, L. AderoMacOpiyo, and S.M. Mureithi. 2016. Are there options outside livestock economy? Diversification among households of northern Kenya. Pastoralism: Research, Policy and Practice 6: 3 . doi:10.1186/s13570-016-0050-4.

Wayua, F.O., M.W. Okoth, and J. Wangoh. 2012. Survey of postharvest handling, preservation and processing practices along the camel milk chain in Isiolo district, Kenya. African Journal of Food, Agriculture, Nutrition and Development 12(7): 6897-6912.

Woldearegay, Y.H., M. Berhanu, and A.T. Mebratu. 2015. Study on management practices and production constraints of camel in Raya-Azebo district, Tigray, Northern Ethiopia. European Journal of Biological Sciences 7(1): 01-06.

Woodford, J.D. 2004. Synergies between veterinarians and para-professionals in the public and privatising animal health services in developing countries. Scientific and Technical Review of the Office International des Epizooties 23(1): 115-135.

Younan, M, and O Abdurahman. 2004. Milk hygiene and udder health. In Milk and meat from the camel. Handbook on products and processing, ed. Z Farah and A Fischer, 67-76. Zurich/singen, Switzerland: Vdf. Hochschulverlag.

\section{Submit your manuscript to a SpringerOpen ${ }^{\circ}$ journal and benefit from:}

- Convenient online submission

- Rigorous peer review

- Open access: articles freely available online

- High visibility within the field

- Retaining the copyright to your article

Submit your next manuscript at $>$ springeropen.com 